\title{
Participation of stem and ear photosynthesis in formation of the crop and its quality in wheat
}

\author{
Vladimir I. Chikov ${ }^{1, *}$, and Guzel A. Akhtyamova ${ }^{1}$ \\ ${ }^{1}$ FRC Kazan Scientific Center of RAS, Kazan Institute of Biochemistry and Biophysics, 420088 \\ Kazan, Russia
}

\begin{abstract}
Photosynthesis of various organs and their contribution to formation of ear caryopsis were measured using ${ }^{14} \mathrm{CO}_{2}$ labeled carbon in the phase of caryopsis formation of spring wheat plants (Moskovskaya-35). It turned out that inclusion of ${ }^{14} \mathrm{C}$ into amino acids is more than twice as high in photosynthesis of an ear. Among labeled low molecular weight compounds in caryopsis, during a short exposure (2 hours) after photosynthesis, the most of the labeled carbon in the ${ }^{14} \mathrm{CO}_{2}$ was found from the photoassimilates of the flag leaf $(70.4 \%)$; from the ear $(55.8 \%)$, and the least - from the stem under the flag $(41.5 \%)$. The difference in inclusion of ${ }^{14} \mathrm{C}$ into the caryopsis' total proteins was observed only with a short exposure of the photosynthesizing organ ( 2 hours). Water-soluble proteins, as products of photosynthesis of the flag leaf, were synthesized for the most in the caryopsis (flag $-73.9 \%$; stem $-46.4 \%$ and ear $-44.8 \%$ ), and in the synthesis of complex proteins, which are soluble in alkali and Triton X-100, most of ${ }^{14} \mathrm{C}$ was from the products of photosynthesis of non-leaf organs $(10.5 ; 21.5 ; 28.4$ and $4.3 ; 12.5 ; 13.4)$, respectively.
\end{abstract}

\section{Introduction}

The first studies of the assimilation activity of the ears were started a long time ago $[1,2]$. It was shown that different chlorophyll organs differ in the daily dynamics of photosynthesis [3], and the photochemical activity of chloroplasts of non-leaf organs, determined by Hill reaction and $\mathrm{CO}^{2}$ fixation, is 2-3 times higher than chloroplasts isolated from flag leaves [4].

Various researchers' assessment on assimilation activity of chlorophyll-containing organs during plant development is significantly different. This is due to the ontogenetic change in the metabolism of various acceptors of photoassimilates [5]. An increase in the metabolic activity of an ear after flowering sharply reduces the supply of root with photoassimilates [6], which leads to a decrease in the entire metabolic activity of the plant due to a decrease in the supply of mineral nutrients to the aerial part of the plant. If you reduce the mass of an ear before the flowering (removing only the top three ears), you can get a significant increase in the final mass of grains compared to the native plant. In addition, at different periods of ontogenesis, the structure of the synthesized substances in the grains will undoubtedly change, and this is an important element in the formation of the quality of the

*Corresponding author: vichikov@bk.ru 
final product. But this side of the issue somehow remained indifferent from the attention of researchers.

In this regard, the objective was to evaluate not only the contribution of non-leaf organs to the overall photosynthesis of a plant, but also the composition of the synthesized substances in caryopses from photosynthesis products transported from different chlorophyllcontaining wheat organs.

\section{Materials and methods}

The experiments were carried out on soft spring wheat cultivars - Moskovskaya 35, which were grown in vegetation vessels with a capacity of $7 \mathrm{~kg}$ of air-dried dark gray forest medium loamy soil with a moisture content of $70 \%$ of the full moisture capacity.

In the phase of caryopsis formation on whole native plants, ${ }^{14} \mathrm{CO}_{2}$ was added using photosynthetic chambers on pins under natural light either to the middle part of the flag leaf's lamina (2.5 cm long) or to the stem section with the leaf sheath (also $2.5 \mathrm{~cm} \mathrm{long}$ ), or the whole ear [3]. The adding was carried out from 10 to 12 hours a day. The exposure time of the photosynthesizing organ in the leaf chamber was 1-2 min, the concentration of ${ }^{14} \mathrm{CO}_{2}$ was at $0.03 \%$ (by volume) with a specific radioactivity of $33 \mathrm{MBq} / \mathrm{mg}$.

In one experiment, after 2 minutes of adding the ${ }^{14} \mathrm{CO}_{2}$ to various wheat organs, the plants were divided into parts (flag leaf, stem above and below the flag leaf node, ear) and fixed in boiling ethanol, followed by analysis of the distribution of ${ }^{14} \mathrm{C}$ between low molecular weight and alcohol-soluble products of photosynthesis [7]. In another parallel experiment, the plants were detached after 2, 6 or 22 hours after 1 -minute addition of ${ }_{14} \mathrm{CO}^{2}$, fixed in liquid nitrogen, and then lyophilized, in order to analyze the distribution of ${ }^{14} \mathrm{C}$ among the final photosynthesis products in ear's caryopses (separated by solubility). The freeze-dried ear was divided into caryopses and bracts with an ear rachilla. Only the grains were analyzed. The milled fixed material was analyzed for the content of ${ }^{14} \mathrm{C}$ in different solubility fractions of substances [8]: extracted with acetone (lipids, pigments); low molecular weight compounds with a mass of less than $6000 \mathrm{kD}$ passing through Baxter dialysis membranes (USA and Canada); water-salt-soluble proteins $(0.1 \mathrm{M} \mathrm{KCl})$; alcohol-soluble proteins ( $80 \%$ ethanol); extracted with alkali $(0.2 \mathrm{M} \mathrm{NaOH})$ and Triton X100), as well as in an insoluble precipitate containing polysaccharides.

Radioactivity of all fractions, except for the insoluble precipitate (its radioactivity was measured using a $5 \mathrm{mg}$ sample), was calculated in a Delta-300 liquid scintillator of "Analytic" (USA) after applying chromatographic paper to the disks. Thus, the radioactivity of all fractions was determined in a cellulose medium (with the same medium's selfabsorption of $\left.{ }^{14} \mathrm{C}\right)$.

Distribution of ${ }^{14} \mathrm{C}$ in individual organs and fractions of the plant was evaluated as a percentage of the amount of their radioactivity. Data are presented as arithmetic mean of five recurrences and their standard errors.

\section{Results and discussion}

Although the photosynthesis of non-leaf organs of a wheat plant per mg of mass is much lower than that of leaves, in total they make up half of the total $\mathrm{CO}_{2}$ assimilation during the caryopses formation (Table 1). Evaluation of the composition of the resulting photosynthesis products (Table 2) showed that photosynthesis in non-leaf organs has a significantly larger non-carbohydrate orientation. To a large extent, this is apparently due to the high export function of the leaves. 
Table 1. Photosynthesis rate of various wheat organs in the phase of the caryopses formation.

\begin{tabular}{|l|c|c|}
\hline \multicolumn{1}{|c|}{ Plant's organ } & $\mathrm{Mg}$ of $\mathrm{CO}_{2} /$ hour per organ & $\%$ \\
\hline Ear & $0.31 \pm 0.07$ & $8.7 \pm 1.9$ \\
\hline Rachilla & $0.52 \pm 0.11$ & $14.7 \pm 4.0$ \\
\hline Flag leaf & $1.02 \pm 0.09$ & $28.6 \pm 2.0$ \\
\hline Stem under the flag leaf & $0.61 \pm 0.06$ & $17.2 \pm 1.5$ \\
\hline $2^{\text {nd }}$ leaf & $0.75 \pm 0.07$ & $21.2 \pm 0.3$ \\
\hline Stem under the $2^{\text {nd }}$ leaf & $0.34 \pm 0.06$ & $9.6 \pm 1.9$ \\
\hline Whole plant & $3.55 \pm 2.1$ & $100 \%$ \\
\hline
\end{tabular}

The main transport compound in most plant species is sucrose. As we presented earlier $[9,10]$, the degree of sucrose hydrolysis in the leaf apoplast by invertase under changes in either light conditions or a "request" for sugar from organs accepting photosynthesis products, is the main regulatory mechanism for matching the intensity of $\mathrm{CO}_{2}$ fixation with the export of photoassimilates from leaves. Since non-leaf organs probably do not have such a mechanism for regulating photosynthesis and the export function of the photosynthetic apparatus, the ratio of ${ }_{14} \mathrm{C}$ labeled sucrose/hexose was significantly lower than that of leaves, especially in the ear (Table 2).

Table 2. Distribution of ${ }^{14} \mathrm{C}$ among low molecular weight compounds in the products of photosynthesis (\%) in the flag leaf, stem and ear in wheat plants after a 2-minute of ${ }_{14} \mathrm{CO}^{2}$ adding.

\begin{tabular}{|l|c|c|c|}
\hline \multicolumn{1}{|c|}{${ }^{14}$ C labeled compounds } & Flag leaf & Stem under the flag leaf & Ear \\
\hline Sucrose & $44.8 \pm 1.8$ & $37.8 \pm 1.1$ & $25.0 \pm 1.6$ \\
\hline Hexose & $8.0 \pm 0.8$ & $10.6 \pm 1.0$ & $9.5 \pm 0.7$ \\
\hline Suxrose/hexose & 5.6 & 3.6 & 2.6 \\
\hline Sugar phosphates & $17.8 \pm 1.8$ & $19.9 \pm 0.3$ & $11.8 \pm 1.8$ \\
\hline Serine, glycine, alanine, aspartate & $17.3 \pm 1.5$ & $17.3 \pm 0.8$ & $39.3 \pm 12.2$ \\
\hline Pigments & $0.9 \pm 0.1$ & $1.4 \pm 0.1$ & $1.5 \pm 0.3$ \\
\hline Other & 11.2 & 13.0 & 12.9 \\
\hline
\end{tabular}

It is known that sucrose enters the apoplast during its transport along the phloem of the stem (due to the high concentration gradient between the phloem and intercellular space) [11]. On the one hand, this creates the possibility of exporting it (with a higher speed [7]) along the stem with an upward flow of water to other organs of the plant (including the ear). But at the same time, the efficiency of sucrose transport along the phloem decreases. Therefore, nature has created a mechanism for capturing sucrose molecules in the apoplast and returning them to sieve tubes [12]. An ear does not have such an opportunity, and sucrose is more successfully exported (apparently symplastically) directly from spikelet bracts to caryopses and is being utilized, as well as non-carbohydrate photosynthesis products. Therefore, the ratio of labeled sucrose/hexose in the ear is the lowest.

An important component of photosynthetic carbon metabolism in leaves is photorespiration and the associated formation of glycolate and its metabolization to amino acids. This is especially pronounced in the ear, where the inclusion of ${ }^{14} \mathrm{C}$ in the products of glycolate metabolism is twice as much as in the leaves and the stem (Table 2). But, as was shown [13], photorespiration does not appear in gas exchange in the non-leaf organs of cereal plants. It is likely that in these organs the products of glycolate metabolism are being export compounds and their formation is not associated with oxygenase photorespiration (oxygen uptake and $\mathrm{CO}_{2}$ emission), but with an excess of the chloroplast's reducing force (the transketolase mechanism of glycolate formation) and use of the produced amino acids (via glycolate) during protein synthesis in acceptor organs. 
Table 3. Distribution of ${ }^{14} \mathrm{C}$-assimilates between different organs of soft spring wheat plants depending on the time elapsed after the ${ }^{14} \mathrm{CO}_{2}$ adding to a flag leaf, stem or ear.

\begin{tabular}{|c|c|c|c|}
\hline \multirow{2}{*}{$\begin{array}{c}\text { Time elapsed after the }{ }^{14} \mathrm{CO}_{2} \\
\text { adding (hours) }\end{array}$} & \multicolumn{3}{|c|}{$\begin{array}{c}\text { Content of }{ }^{14} \mathrm{C} \text {-assimilates, } \% \text { of the radioactivity of the } \\
\text { aerial parts of the plant }\end{array}$} \\
\hline & Flag leaf & Stem & Ear \\
\hline \multicolumn{4}{|c|}{${ }^{14} \mathrm{C}$ donor - flag leaf } \\
\hline 2 & $79.2 \pm 3.2$ & $9.2 \pm 1.0$ & $10.6 \pm 2.3$ \\
\hline 6 & $79.9 \pm 3.5$ & $7.2 \pm 0.4$ & $12.9 \pm 3.7$ \\
\hline 22 & $26.6 \pm 3.2$ & $14.8 \pm 2.0$ & $58.6 \pm 2.9$ \\
\hline \multicolumn{4}{|c|}{${ }^{14} \mathrm{C}$ donor - stem } \\
\hline 2 & $14.1 \pm 1.1$ & $48.8 \pm 3.2$ & $37.1 \pm 3.8$ \\
\hline 6 & $8.4 \pm 0.9$ & $28.5 \pm 2.9$ & $63.1 \pm 3.9$ \\
\hline 22 & $10.2 \pm 1.4$ & $28.6 \pm 1.9$ & $61.2 \pm 1.8$ \\
\hline \multicolumn{4}{|c|}{${ }^{14} \mathrm{C}$ donor - ear } \\
\hline 2 & $5.8 \pm 0.6$ & $6.1 \pm 0.7$ & $88.1 \pm 1.0$ \\
\hline 6 & $6.3 \pm 0.8$ & $5.6 \pm 0.3$ & $88.1 \pm 0.9$ \\
\hline 22 & $5.5 \pm 0.8$ & $5.3 \pm 1.0$ & $89.2 \pm 1.4$ \\
\hline
\end{tabular}

Analysis of the distribution of ${ }^{14} \mathrm{C}$ assimilates in the plant revealed significant differences in their transport from different organs (Table 3). In the daytime (2 and 6 hours after the ${ }^{14} \mathrm{CO}_{2}$ adding), ${ }^{14} \mathrm{C}$-assimilates flowed from the leaf to the ear to a lesser extent than from the stem. In the dark time of the day (in the range from 6 to 22 hours), the outflow from the leaf continued, but stopped from the stem with the leaf sheath. Perhaps this is due to the fact that transport was constantly sustained by acting photosynthesis in the daytime, and the newly synthesized transport products of ${ }^{14} \mathrm{C}$-assimilates were quickly depleted in the dark. The outflow of ${ }^{14} \mathrm{C}$-assimilates from the ear to other organs was negligible, regardless of the time elapsed after the ${ }^{14} \mathrm{CO}_{2}$ adding. Most likely, the transport of photoassimilates from the spikelet bracts is focused only on caryopses and remains inside the ear itself. As for the distribution of labeled photoassimilates of different assimilating organs between the caryopses and ear's spikelet bracts, this indicator did not differed much (from 40\% to 45\%), regardless of the accepting organ.

Table 4. Distribution of ${ }^{14} \mathrm{C}$ among various fractions of labeled substances in ears' caryopses (\%), which were transported from various assimilated ${ }^{14} \mathrm{CO}_{2}$ wheat organs.

\begin{tabular}{|c|c|c|c|c|}
\hline $\begin{array}{c}\text { Time elapsed after } \\
\text { the }{ }^{14} \mathrm{CO}_{2} \text { adding of } \\
\text { photosynthesizing } \\
\text { organ (hours) }\end{array}$ & $\begin{array}{c}\text { Lipid } \\
\text { pigments }\end{array}$ & $\begin{array}{c}\text { Low molecular } \\
\text { weight } \\
\text { compounds }\end{array}$ & Proteins & Polysaccharides \\
\hline 2 & $3.2 \pm 0.3$ & $70.4 \pm 9.3$ & $26.0 \pm 1.2$ & $0.4 \pm 0.3$ \\
\hline 6 & $2.9 \pm 0.7$ & $46.9 \pm 8.9$ & $49.8 \pm 8.9$ & $0.4 \pm 0.2$ \\
\hline 22 & $3.1 \pm 0.2$ & $30.3 \pm 3.6$ & $64.9 \pm 3.4$ & $1.7 \pm 0.1$ \\
\hline & & Donor - stem & & \\
\hline 2 & $4.7 \pm 1.8$ & $41.5 \pm 4.9$ & $52.8 \pm 4.5$ & $1.0 \pm 0.2$ \\
\hline 6 & $5.9 \pm 0.8$ & $32.8 \pm 2.9$ & $59.2 \pm 4.7$ & $2.1 \pm 1.3$ \\
\hline 22 & $6.2 \pm 1.2$ & $25.9 \pm 3.4$ & $66.7 \pm 4.1$ & $1.2 \pm 0.1$ \\
\hline & & Donor - ear & & \\
\hline 2 & $4.7 \pm 1.7$ & $55.8 \pm 5.2$ & $38.8 \pm 4.7$ & $0.7 \pm 0.1$ \\
\hline 6 & $4.2 \pm 1.5$ & $40.2 \pm 2.9$ & $54.4 \pm 2.9$ & $1.2 \pm 0.2$ \\
\hline 22 & $4.5 \pm 1.1$ & $33.5 \pm 2.4$ & $60.7 \pm 5.8$ & $1.3 \pm 0.4$ \\
\hline
\end{tabular}


Photosynthesis products from different photosynthesizing organs of plants were utilized differently in the caryopses. But this difference was manifested only in the fraction of low molecular weight compounds and in short time intervals (Table 4) (2 hours after the ${ }^{14} \mathrm{CO}_{2}$ assimilation of photosynthesis products by the donor organ). After 6 hours, this difference was reduced, and after a day it practically disappeared. From this we can conclude that all these differences appear only during active photosynthesis and are associated with the peculiarities of the transport of photosynthesis products to acceptor organs.

The distribution of the ${ }^{14} \mathrm{C}$-label among individual groups of labeled substances in the caryopses revealed a large difference in the post-photosynthetic use of "own" (synthesized by the assimilating organ itself) or "alien" (received from other organs) photoassimilates (Table 5). An analysis of the fractional composition of the caryopses' proteins synthesized from the photosynthesis products of various wheat organs showed that mainly water-saltsoluble proteins are formed in the caryopses' flag leaf (more than $70 \%$ of all proteins). And structural proteins (soluble in Triton X-100 or alkali) are produced from the photosynthesis products of non-leaf organs by 2-3 times more.

Table 5. Inclusion of ${ }^{14} \mathrm{C}$ in various protein fractions of ear's caryopses, depending on the ${ }^{14} \mathrm{CO}_{2}$ adding to different organs of spring wheat plants.

\begin{tabular}{|c|c|c|c|}
\hline \multirow{2}{*}{ Protein fraction } & \multicolumn{3}{|c|}{ Donor of ${ }^{14} \mathrm{C}$ photosynthesis products } \\
\cline { 2 - 4 } & Flag leaf & Stem & Ear \\
\hline Water-salt-soluble & $73.9 \pm 2.7$ & $46.4 \pm 3.4$ & $44.8 \pm 2.1$ \\
\hline Alcohol-soluble & $10.9 \pm 1.3$ & $19.6 \pm 2.4$ & $13.4 \pm 1.3$ \\
\hline Akali-soluble & $10.9 \pm 1.5$ & $21.5 \pm 2.3$ & $28.4 \pm 5.4$ \\
\hline Soluble in Triton X-100 & $4.3 \pm 1.4$ & $12.5 \pm 1.9$ & $13.4 \pm 2.7$ \\
\hline
\end{tabular}

This suggests that complex amino acids, which are likely to be transported only symplastically, flow from non-leaf organs to caryopses to a greater extent. It is they (arginine, proline, tyrosine, tryptophan, phenylalanine, threonine, cysteine) that are not among the primary products of photosynthesis, but participate in the formation of turns, branches and additional bonds in polypeptide chains, which further contribute to the formation of the necessary conformation of protein reaction centers. This question probably matters not only for cereal plants. Such a difference in the final products of the photosynthesis of acceptor organs when using different donors of photoassimilates can also occur in the synthesis of biologically active substances in medicinal plants. The study of this problem is probably important in the selection of medicinal plants.

\section{Conclusion}

Thus, non-leaf photosynthetic organs of cereal plants play an important role in shaping the quality of economically important products. The most important element of this regulation is probably the competition between different acceptor organs for the production of photosynthesis products. Very fast and powerful response of roots to the redistribution of photosynthesis products between different acceptor organs (for example, by reducing the ear capacity by only three ears), which was discovered by us earlier [5 p. 137], indicates the important regulatory value of this particular plant organ. The mechanisms for the occurrence of such a difference in the ratio of caryopses' final products that are formed from different donor-organs of photosynthesis products are not yet understood. What signals accompany the flow of photoassimilates from different organs to the ear and how are they separated? What is important in these metabolic processes, the composition of the low molecular weight products of photosynthesis arising from various donors, or some specific activation of the 
corresponding genes in the acceptor that are necessary for the synthesis of such complex proteins?

We can only confidently say that the launch of these mechanisms occurs as a result of disruption of stationary flows of substances in the plant. And this relationship is determined not only by a change in the plant's own metabolism, but also by increased activity of the symbiosis of the plant with soil microbes. Plant biologists are not paying enough attention to this crucial issue. After all, the two-meter deep chernozems were formed without any mineral fertilizers. And human activity, first of all, the so-called idea of "Programming the crop", led to the fact that half of the organic matter of the soil over the past 100 years (precisely for this reason) has been lost. This is an important indicator of the symbiosis of plants with microorganisms. To this day, almost any agronomist, when discussing the problem of increasing the yield, says that it is necessary to compensate the soil for N, P, and K seized by the crop. At the same time, we showed in 2017 https://regnum.ru/news/innovatio/2374286.html?t $=1517388452$ that, due to the intensification of the export of sugars from leaves to roots, their mass can be increased by 2 3 times.

Namely, this is the bridgehead for increasing the symbiosis of microorganisms with the plant. Accordingly, the symbiotic activity of the plant with microbes also increases. It is only necessary to additionally provide the roots with photosynthesis products. It is also important that this additional consumption of photosynthesis products does not overload or inhibit the photosynthesis process itself. As has long been shown [14, 15], the intensity of photosynthesis depends on the "request" for photoassimilates from acceptor organs. The more "request" - the more intense photosynthesis. And this means that with high photosynthesis, protection of chloroplast structures from photodestruction by light quanta is better.

\section{References}

1. B. A. Mitrofanov, A. S. Okanenko, B. I. Gulyaev at al. Znachenie otdel'nyh organov rastenij pshenicy $v$ fotosinteze poseva. Fotosintez $i$ ispol'zovanie solnechnoj energii [Significance of individual organs of wheat plants in the photosynthesis of crops. Photosynthesis and the use of solar energy]. (Nauka, Leniingrad, 1971)

2. E. Y. Sambo, J. Moorby, F. Z. Milthorpe, Austral. J. Plant Physiol. 4, 713 (1977). DOI: 10.1071/PP9770713

3. V. I. Chikov, V. V. Lozovaya, I. A. Tarchevsky, Russian Journal of Plant Physiology. 24, 691 (1977)

4. N. Maitra, S.P. Sen, Photosynthetica, 21, 515 (1987)

5. V. I. Chikov, Fotosintez i transport assimilyatov [Photosynthesis and transport of assimilates] (Nauka, Moscow, 1987)

6. V. I. Chikov, S. B. Chemikosova, et al., Russian Journal of Plant Physiology 31, 475 (1984)

7. V. I. Chikov, N. Y. Avvakumova, G. G. Bakirova, L. A. Belova, L. M. Zaripova, Biologia Plantarum 44, 517 (2001). DOI: 10.1023/A:1013778201203

8. B. P. Pleshkov Praktikum po biohimii rastenij [Workshop on plant biochemistry] (Kolos, Moscow, 1968)

9. V. I. Chikov, G. A. Akhtyamova, S. N. Batasheva, A. L. Mikhailov, L. A. Khamidullina, O. A. Timofeeva, Russian Journal of Plant Physiology 62, 39 (2015). DOI: 10.1134/S1021443715010045 
10. V. I. Chikov, A. L. Mikhailov O. A. Timofeeva, L. A. Khamidullina, Russian Journal of Plant Physiology 63, 70 (2016). DOI: 10.1134/S1021443716010040

11. P. E. H. Minchin, G. S. McNaughton, Aust. J. Plant Physiol. 14, 325 (1987)

12. B. G. Ayre, F. Krller, R. Turgeon, Plant Physiol. 131, 1518 (2003). DOI: 10.1104/pp.012054

13. N. S. Balaur, V. A. Vorontsov, L. F. Merenyuk, Russian Journal of Plant Physiology 60, 184 (2013)

14. F. Lenz, Ztschr. Pflanzenenernahr und Bodenk. 140, 51 (1977)

15. A. J. Hall, C. J. Brady, Austral. J. Plant Physiol. 4, 771 (1977). DOI: 10.1071/PP9770771 